\title{
Groundwater Level Prediction Using Artificial Neural Network Model
}

\author{
Pallavi Porte $^{1 *}$, Rajendra Kumar Isaac ${ }^{1}$, Kipoo Kiran Singh Mahilang ${ }^{2}$, \\ Khilendra Sonboier ${ }^{3}$ and Pankaj Minj ${ }^{3}$ \\ ${ }^{1}$ Department of WRE, SHIATS, Allahabad, UP, India \\ ${ }^{2}$ Department of FMP, SVCAET\&RS, IGKV, Raipur, India \\ ${ }^{3}$ Department of APFE, SHIATS, Allahabad, UP, India \\ *Corresponding author
}

\section{A B S T R A C T}

\begin{tabular}{|l|}
\hline K e y w o r d s \\
Artificial neural network, \\
$\begin{array}{l}\text { Groundwater level, } \\
\text { Rainfall, Levenberg } \\
\text { Marquardt algorithm }\end{array}$ \\
\hline Article Info \\
\hline $\begin{array}{l}\text { Accepted: } \\
\text { 26 January } 2018 \\
\text { Available Online: } \\
\text { 10 February } 2018\end{array}$ \\
\hline
\end{tabular}

\section{Introduction}

Groundwater is a highly valuable resource. Measurement and analysis of groundwater level is needed for maintaining groundwater availability. The accurate prediction of groundwater levels is essential for sustainable utilization and management of vital groundwater resources. The consumption of water increases every day with the growth in population. The ground water level is going down day by day. In India, groundwater serves about $80 \%$ of rural population, $50 \%$ of urban population and about $60 \%$ of agricultural area. For management of groundwater level a model is required which
Forecasting of stream flow and ground water level changes became an important component of water resources system control and challenging task for water resources engineers and managers. The ground water level data and rainfall data of twenty years from 1996 to 2015 were collected. Artificial neural network (ANN) is used to predict water resources variable. The model was trained, validated and tested for randomly divided samples. The regression analysis shows good correlation between each other thin the range 0.12 to 0.97 of Abhanpur block. The performance evaluation of ANN (n) 0.9781 during training for the month March/April/May of Abhanpur block. Thus it can be determined that ANN provides a feasible method in predicting groundwater level in Raipur district of Chhattisgarh state. 
In this paper artificial neural network model were developed. The present paper considers the development of ANN model for prediction of GWL (Cobaner et al., 2016).

\section{Materials and Methods}

\section{Study area}

The area Abhanpur block is located at the Raipur District of Chhattisgarh State, India. Raipur is situated in East Central part of Chhattisgarh at latitude of $22^{\circ} 33 \mathrm{~N}$ to $21^{\circ} 14 \mathrm{~N}$, longitude $82^{\circ} 6 \mathrm{E}$ to $81^{\circ} 38 \mathrm{E}$ and altitude $289.5 \mathrm{~m}$ above mean sea level and district covers $226 \mathrm{~km}^{2}$ (87 Sq. m.) areas. The study area comes under sub-tropical type of climate. Maximum temperature reaches to $41^{\circ} \mathrm{C}$ and minimum temperature reaches $10-15^{\circ} \mathrm{C}$. Ground water level data for 1996-2015 was obtained from Central Ground Water Board (CGWB), Raipur district of Chhattisgarh state and Rainfall data from the Department of Agro-meteorology, College of Agriculture, IGKV, Raipur (C.G.).

\section{Levenberg-Marquardt Training algorithm}

The Levenberg-Marquardt method is a modification of the classic Newton algorithm for finding an optimum solution to a minimization problem. The update rule of the Gauss-Newton algorithm is presented as

$\mathrm{X}_{\mathrm{k}+1}=\mathrm{X}_{\mathrm{k}}-\left[\mathrm{J}^{\mathrm{T}} \mathrm{J}\right]^{-1} \mathrm{~J}^{\mathrm{T}} \mathrm{e} \ldots$

In order to make sure that the approximated Hessian matrix $\mathbf{J}^{\mathrm{T}} \mathbf{J}$ is invertible, LevenbergMarquardt algorithm introduces another approximation to Hessian matrix:

$\mathrm{H}=\mathrm{J}^{\mathrm{T}} \mathrm{J}+\mu \mathrm{I} \ldots(2)$

It uses and approximation to the Hessian matrix in the following Newton-like weight update
$\mathrm{X}_{\mathrm{k}+1}=\mathrm{X}_{\mathrm{k}}-\left[\mathrm{J}^{\mathrm{T}} \mathrm{J}+\mu\right]^{-1} \mathrm{~J}^{\mathrm{T}} \mathrm{e} \ldots$ (3)

Where $\mathrm{x}$ the weights of neural network, $\mathrm{J}$ the Jacobian matrix of the performance criteria to be minimized, $\mu$ a scalar that controls the learning process and $\mathrm{e}$ the residual error vector. Levenberg-Marquardt has great computational and memory requirements and thus it can only be used in small networks (Kumar, Indian and Khan 2013).

\section{Performance evaluation criteria}

To judge the prediction performance of a network, MSE, and correlation coefficient (R) between network output and network target outputs in three training, testing and validation groups were used and calculated as follows:

$$
\begin{aligned}
& \text { MSE }=\frac{\sum_{1=1}^{\mathrm{n}}\left((\mathrm{yi}-\overline{\mathrm{y}})^{2}\right)}{\mathbf{n}} \ldots(4) \\
& \mathbf{R}=\sqrt{\mathbf{1}-\frac{\sum\left((y \bar{i}-\overline{y i})^{2}\right)}{\sum y i^{2}-\frac{\sum \bar{y}^{2}}{n}}} \ldots(5)
\end{aligned}
$$

Where, yi is actual data and $\bar{y}$ is calculated data by network. Zero is the best condition for MSE and one is the most desirable condition for R. (Kumar, Indian and Khan 2013)

\section{Results and Discussion}

This chapter deals with the results related to development of optimized ANN MODELs for Groundwater level prediction. Table 1 shows the calculated values of mean, standard deviation, skewness and variance for different months.

Figure 2 to 5 shows the relation between Actual Groundwater level and Normalised groundwater level for different months of Abhanpur block of Raipur District of Chhattisgarh State. 
Table.1 Statistical Analysis of Groundwater Level of Abhanpur

\begin{tabular}{|l|l|l|l|l|} 
& Jan & Mar & Aug & Nov \\
\hline Mean & 2.4575 & 3.0367 & 0.476 & 1.166 \\
\hline SD & 0.6622 & 2.0600 & 0.2644 & 0.2862 \\
\hline Skewness & 0.1781 & 0.5958 & 0.9293 & 1.1911 \\
\hline Variance & 0.4386 & 4.2437 & 0.0699 & 0.0819 \\
\hline
\end{tabular}

Table.2 Optimized ANN Model for Abhanpur

\begin{tabular}{|l|l|}
\hline Month & ANN model \\
\hline January (Post Monsoon Rabi) & $\mathrm{P} 1 * \mathrm{X}+\mathrm{P} 2=0.7 * 0.151+0.02$ \\
\hline March/Apri/May (Pre Monsoon) & $\mathrm{P} 1 * \mathrm{X}+\mathrm{P} 2=0.77 * 1.162+0.02$ \\
\hline August (Monsoon) & $\mathrm{P} 1 * \mathrm{X}+\mathrm{P} 2=0.23 * 0.108+0.03$ \\
\hline November (Post Monsoon Kharif) & $\mathrm{P} 1 * \mathrm{X}+\mathrm{P} 2=0.21 * 0.104+0.11$ \\
\hline
\end{tabular}

Table.3 Regression Values of Abhanpur Block

\begin{tabular}{|l|c|c|c|c|}
\hline Samples & Jan & Mar & Aug & Nov \\
\hline Training & 0.6657 & 0.9781 & 0.8484 & 0.3518 \\
\hline Validation & 0.8667 & 0.9951 & 0.9032 & 0.77373 \\
\hline Testing & 0.17581 & 0.9545 & 0.76495 & 0.85017 \\
\hline
\end{tabular}

Fig.2 Relation between Observed G.W.L. and Normalized G.W.L. of Abhanpur for January Month

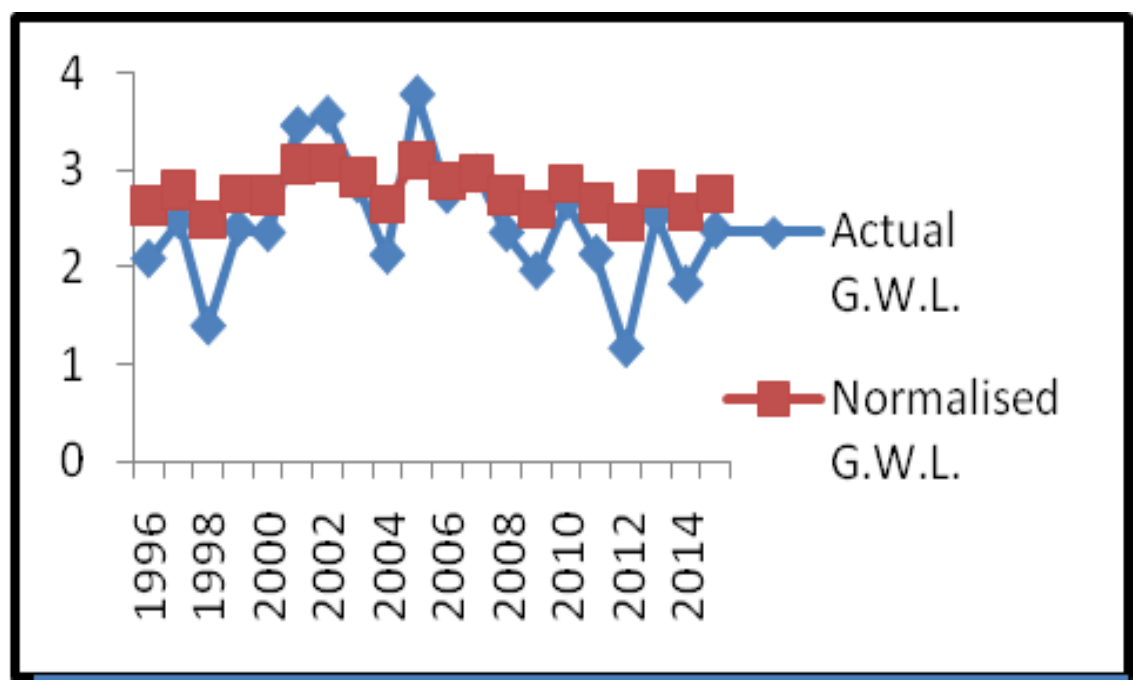


Fig.3 Relation between Observed G.W.L. and Normalized G.W.L. of Abhanpur for March/April/May Month

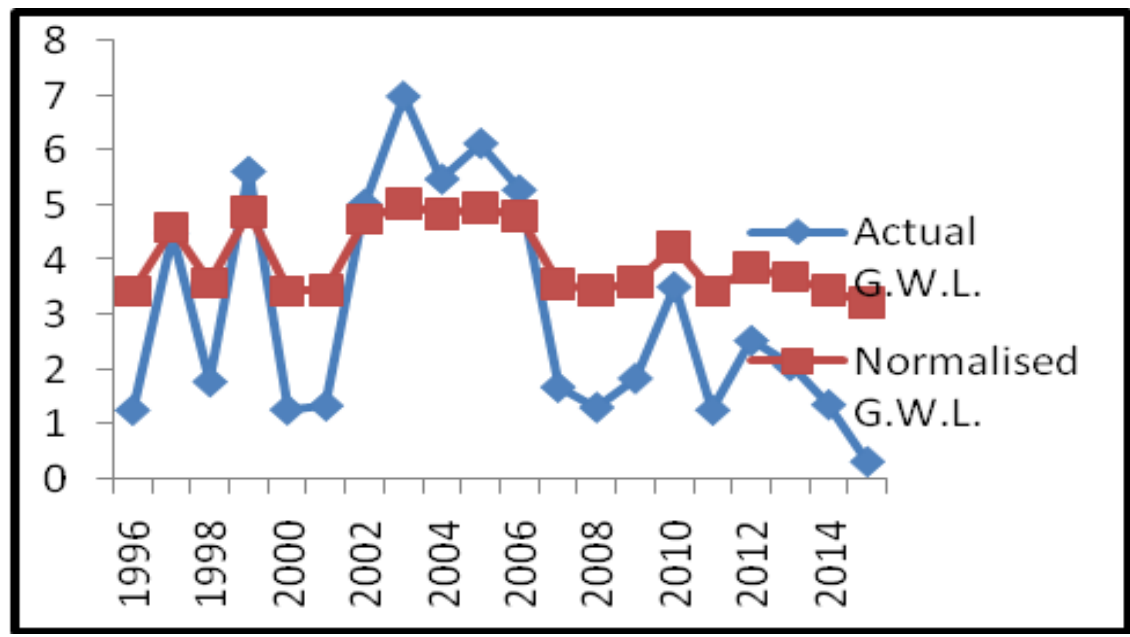

Fig.4 Relation between Observed G.W.L. and Normalized G.W.L. of Abhanpur for August Month

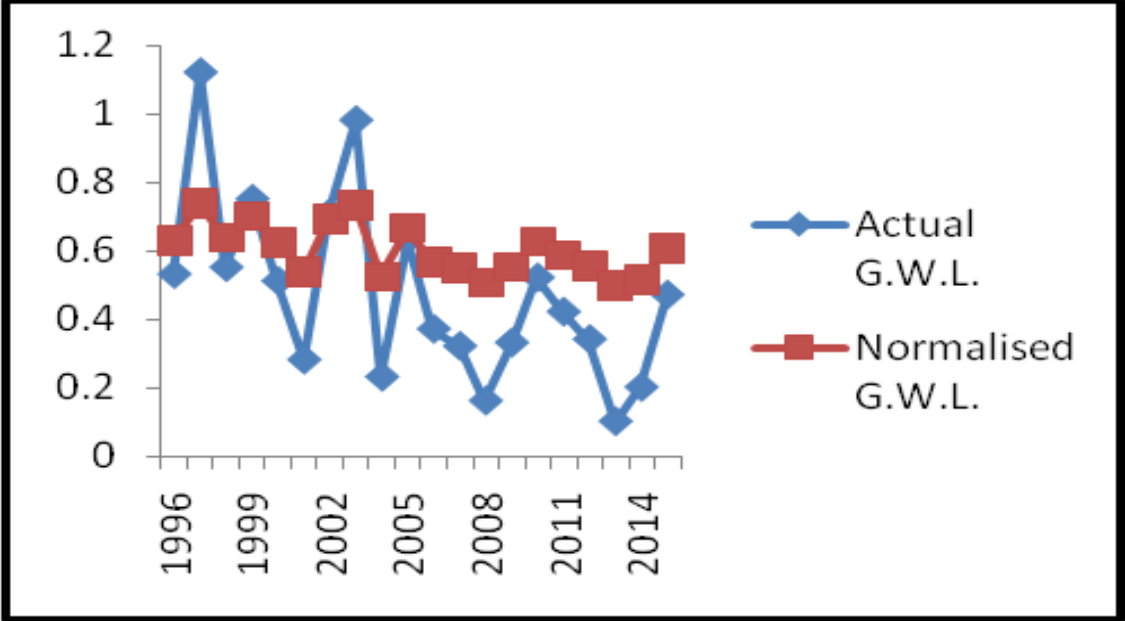

Fig.5 Relation between Observed G.W.L. and Normalised G.W.L. of Abhanpur for November Month

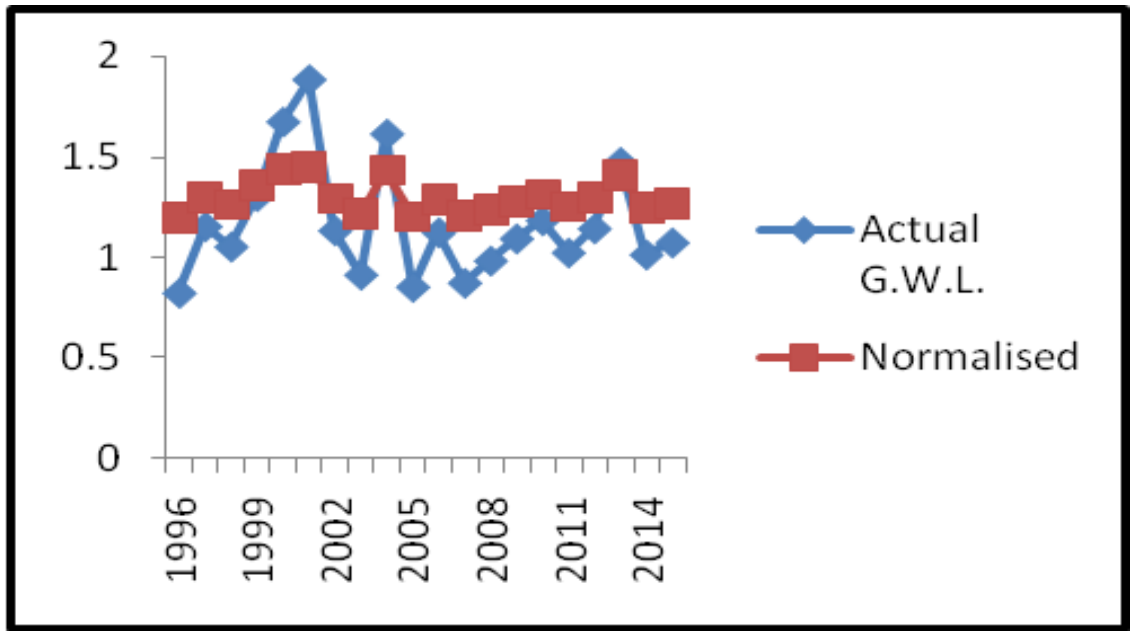


Fig.6 Shows the optimized Artificial Neural Network Model. Trend line shows that the groundwater level increases in the month of January, August and November. Groundwater level decreases in the month of March/April/May.

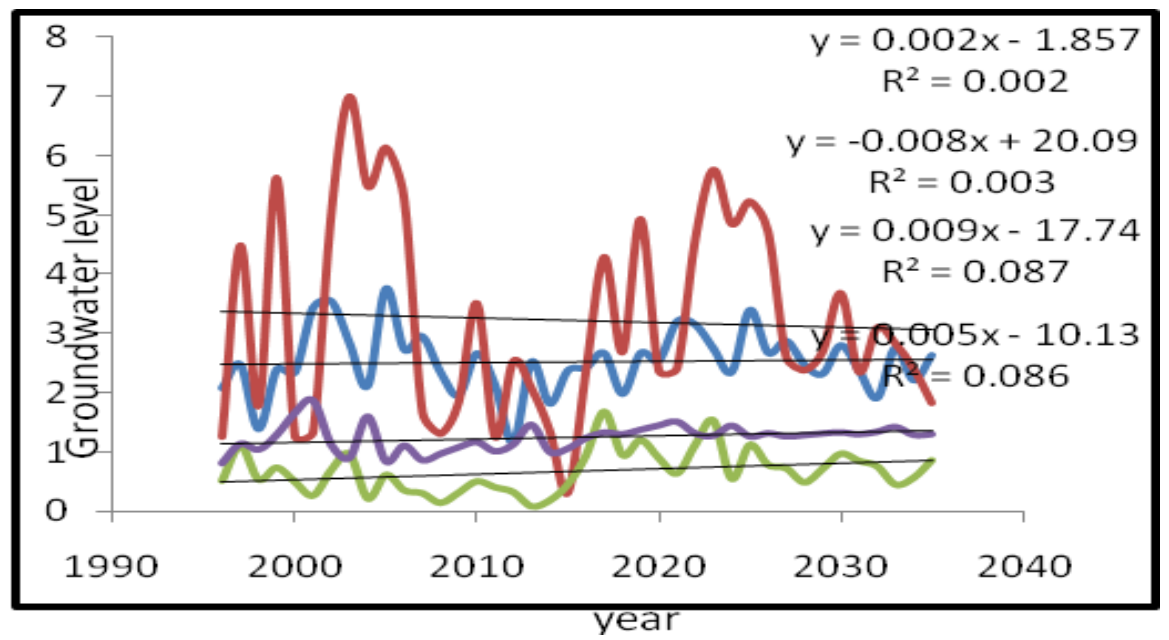

Fig.7 Map of Raipur district of Chhattisgarh state, India

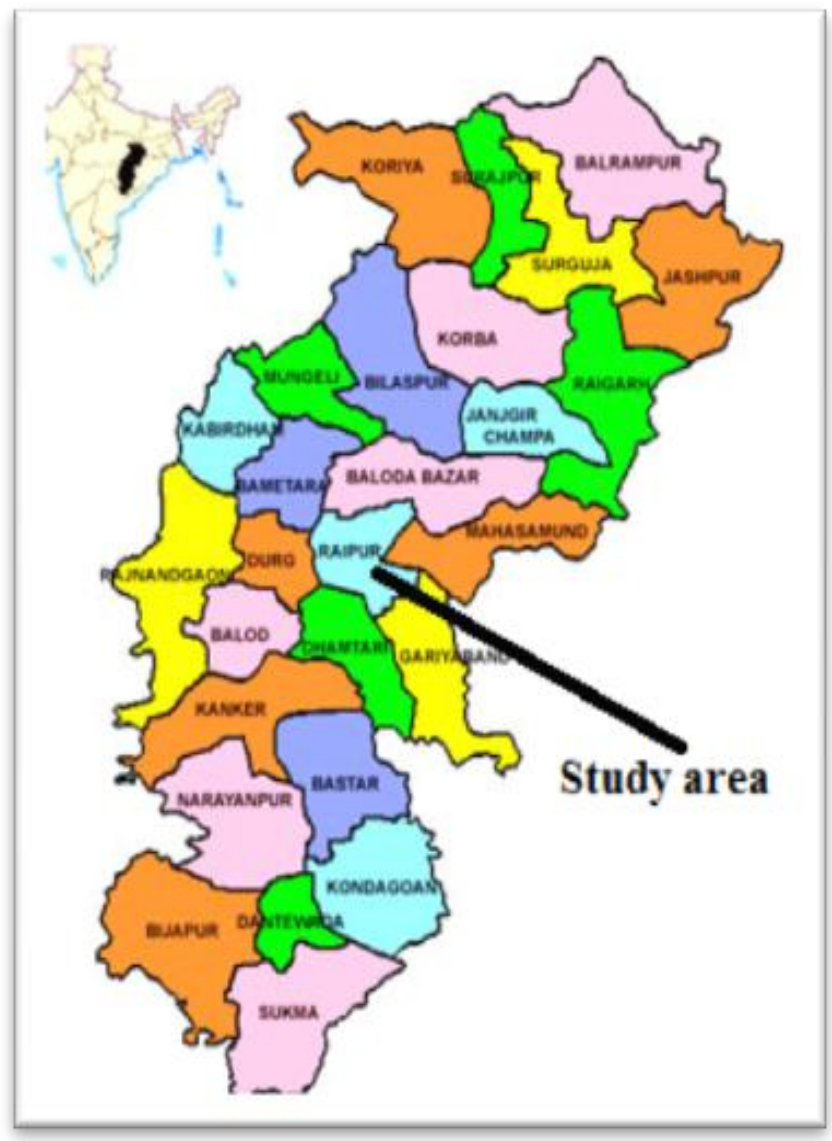


Fig.8 Regression Line of Outputs and Targets for January, March, August and November Month of Abhanpur Block
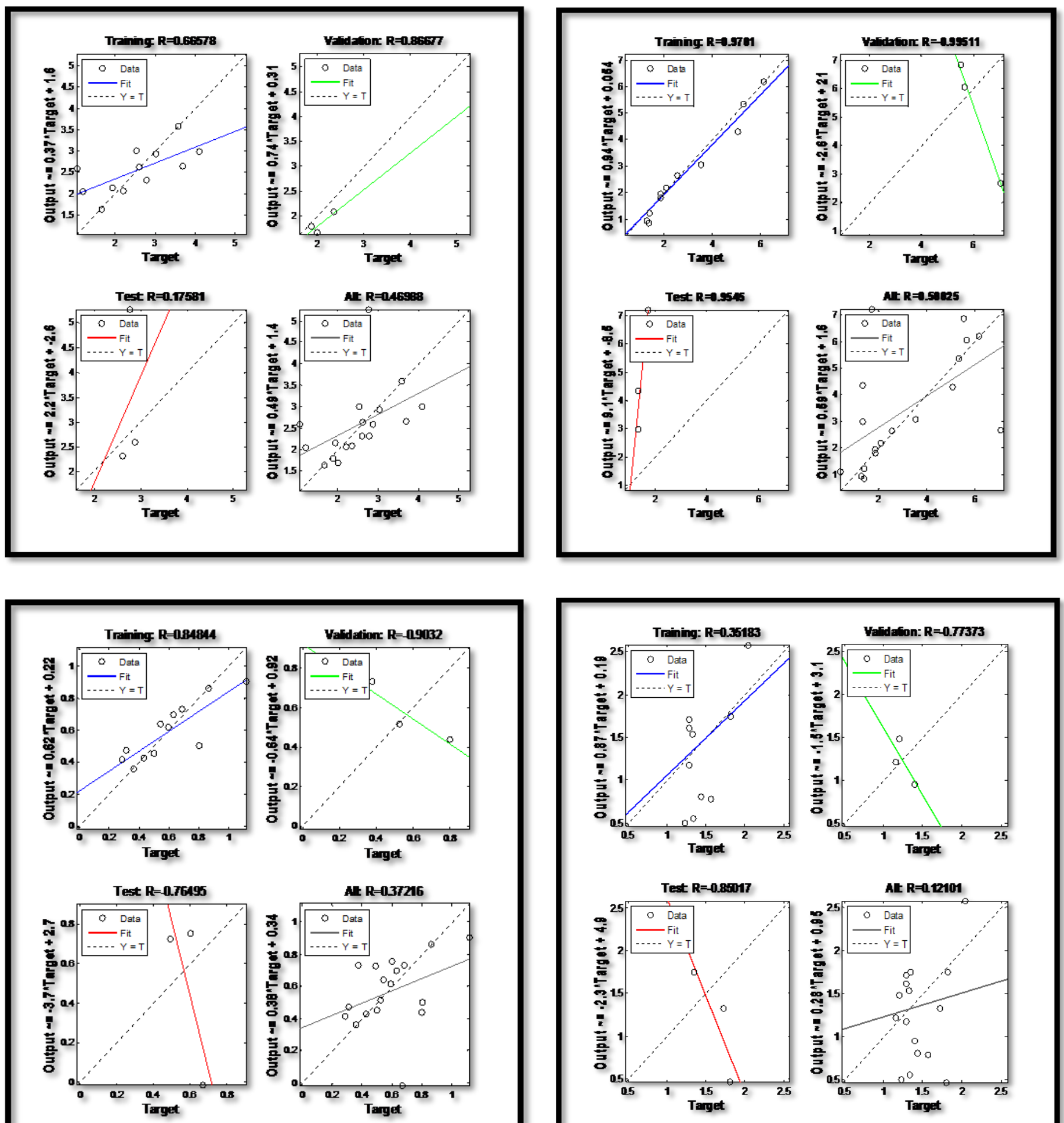


\section{Development of optimized Artificial Neural Network Model}

Table 2 shows the optimised ANN model generated for different months viz. January, March/April/May, August and November of Abhanpur block.

\section{Regression analysis}

The regression analysis is done to determine the values of parameters for a function causing the function to best fit a set of data observation. Regression is used to analyzed the relation between two continuous (scale) variables. Table 3 shows the regression values of different month viz. January, March/April/May, August and November.

Figure 8 shows the regression line of outputs and targets for different months of Abhanpur block.

The developed models were then validated and tested using ANN for the further accuracy in the model generated. The regression value of training, testing and validation varies between 0.9781 to 0.12101 which shows the good correlation between the output and target data set.

The following conclusions were drawn from the present study as enumerated below:

The performance evaluation of ANN model showed highest value of correlation coefficient (R) as 0.9781 during training for the month March/April/May of Abhanpur block of Raipur District (C.G.).

The regression analysis shows good correlation between each other within the range 0.12 to 0.97 of Abhanpur block.

The optimized ANN models were developed successfully resulting best fit curve.

\section{References}

Affandi, A. K. and Watanabe, K. 2007. Daily groundwater level fluctuation forecasting using soft computing technique, Nature and science. 5(2), 110.

Alvisi, S., Mascelluni, G., Franchini, M. and Bardossy, A. 2006. Water level forecasting through fuzzy logic and artificial neural network approaches, Hydrology and earth system sciences. 10, 1-17.

Cobaner, M., Babayigit, B. and Dogan, A. 2016. Estimation of groundwater level in floridan aquifer system using surface water and climate observations based on the genetic programming, Journal AWWA. 1-49.

Coppola, Jr. E. A., Mclane, C. F., Poulton, M. M., Szidarovszky, F. and Magelky, R. D. 2005. Predicting conductance due to upcoming using neural networks, Ground water. 43, 827-836.

Daliakopoulos, I. N., Coulibaly, P. and Tsanis, I. K. 2005. Groundwater level forecasting using artificial neural networks, Journal of hydrology. 309, 229-240.

Jalalkamali, A., Sedghi, H., and Manshouri, M. 2011. Monthly groundwater level prediction using ANN and neuro-fuzzy model: a case study on kerman plain, iron, Journal of Hydro informatics. 13.4, 867-876.

Kumar, S., Indian, A. and Khan, Z. 2013. Neural network model for prediction of groundwater level in metropolitan considering Rainfall-Runoff as a parameter, International journal of soft computing and engineering (IJSCE). 3, 195-198.

Maedeh, P.A., Mehrdadi, N., Nabi Bidhendi, G.R. and Abyaneh, H.Z. 2013. Application of artificial neural network to predict total dissolved solids 
variations in groundwater of Tehran plain, Iran, International journal of environment and sustainability. 2, 1020.

Matta, S. 2011. Predicting groundwater levels using linear regression and neural networks, CS. 229, 1-5.

Nayak, P. C., Satyaji Rao, Y. R. and Sudheer, K. P. 2006. Groundwater level forecasting in a shallow aquifer using Artificial neural network approach. 20, 77-90.
Sahoo, S. and Jha, N. K. 2013. Groundwater level prediction using multiple linear regression and artificial neural network techniques: a comparative assessment, Hydrology journal. 21, 1865-1887.

Wangsu, M., 2015. Development of optimized ANN models for estimating rainfall intensity at Ranikhola watershed, Gangtok, Unpublished M. Tech project report. Vaugh school of Agricultural Engineering and Technology, SHIATS in Allahabad.

\section{How to cite this article:}

Pallavi Porte, Rajendra Kumar Isaac, Kipoo Kiran Singh Mahilang, Khilendra Sonboier and Pankaj Minj. 2018. Groundwater Level Prediction Using Artificial Neural Network Model. Int.J.Curr.Microbiol.App.Sci. 7(02): 2947-2954. doi: https://doi.org/10.20546/ijcmas.2018.702.358 